\title{
Microwave Dielectric Properties of Ti-Te system Ceramics for Triplexer Filter
}

\author{
Eui-Sun Choi ${ }^{\dagger}$, Moon-Woo Lee**, Sang-Hyun Lee**, Gu-Hong Kang***, \\ Gap-Sul Kang**** and Young-Hie Lee*
}

\begin{abstract}
In this study, the compositions for the microwave dielectric materials were investigated to obtain the improved dielectric properties, the high temperature stability, and the sintering temperature of less than $900{ }^{\circ} \mathrm{C}$, which was necessary for cofiring with the internal conductor of silver. In addition, the dielectric sheets were prepared by the tape casting technique, after which the sheets were laminated and sintered. In this process, the optimum ratio of powder and binder, laminating pressure, temperature, and possibility for cofiring with the internal conductor were studied. Finally, multilayer chip treplexer filter for the $800-2,000 \mathrm{MHz}$ range were fabricated, and the frequency characteristics of the triplexer filter were investigated. When the $0.6 \mathrm{TiTe}_{3} \mathrm{O}_{8}-0.4 \mathrm{MgTiO}_{3}+3 \mathrm{wt} \% \mathrm{SnO}+7 \mathrm{wt} \% \mathrm{H}_{3} \mathrm{BO}_{3}$ ceramics were sintered at $820{ }^{\circ} \mathrm{C}$ for 0.3 hours, the microwave dielectric properties of the dielectric constant of 29.91 , quality factor of $33,000 \mathrm{GHz}$, and temperature coefficient of resonant frequency of $-2.76 \mathrm{ppm} /$ ${ }^{\circ} \mathrm{C}$ were obtained. Using the Advanced Design System (ADS) and High Frequency Structure Simulator (HFSS), the multilayer chip triplexer filter acting at the range of $800-2,000 \mathrm{MHz}$ were simulated and manufactured. The manufactured triplexer filter had the excellent frequency properties in the CDAM800, GPS and PCS frequency regions, respectively.
\end{abstract}

Keywords: LTCC, Triplexer, Microwave dielectric properties, Ti-Te

\section{Introduction}

The usage of mobile communication devices has rapidly increased due to the advancements in the electronic industry and the emergence of the information-oriented society. The increase in demand for mobile communication devices was led by personal mobile terminal in the UHF range of $300 \mathrm{MHz}-3 \mathrm{GHz}$ ) [1, 2]. The demand for miniaturization and lightweight devices requires smaller and multifunctional electronic components, such as the RF filter, which is considered to be bulky and heavy. In addition, surface mounting of this device (SMD) is inevitable. Therefore, multi-layer technologies, such as multi-layer capacitor and tape casting have received great attention from researchers in recent years [3, 4]. In addition, loss of resistance of the internal conductor in multi-layered devices significantly affects the performance of such devices within the microwave range of several hundred MHzs. An internal conductor should utilize materials with high con-

$\dagger \quad$ Corresponding Author: Department of Electronic Materials Engineering, Kwangwoon Univerity, Korea. (sunsee@kw.ac.kr)

* Department of Electronic Materials Engineering, Kwangwoon Univerity, Korea. (yhlee@kw.ac.kr)

** Department of Ubiquitous Communication, Seoul Jeongsu College of Korea Polytechnic I . (mwlee@nate.com, sanghyunlee@kopo. ac.kr)

*** Department of Photoelectron, Seongnam College of Korea Polytechnic, Korea. (kgh33@kopo.ac.kr)

**** Department of Computer-Aided Machining, Hwaseong College of Korea Polytechnic II, Korea. (kab312@kopo.ac.kr)

Received: May 25, 2010; Accepted: December 7, 2010 ductivity, such as silver $\left(\mathrm{Ag}, \mathrm{m} . \mathrm{p} .=961^{\circ} \mathrm{C}\right)$ or copper $(\mathrm{Cu}$, m.p. $\left.=1064^{\circ} \mathrm{C}\right)[5,6]$. In case that Low Temperature Cofired Ceramics (LTCC) technology is applied for device manufacturing, sintering of dielectric material should be conducted at a temperature, which is less than the melting point of conducting metal.

The dielectric in the $\mathrm{TiO}_{2}-\mathrm{TeO}_{2}$ system among the developed LTCC materials is a highly promising material due to the low temperature required in sintering [7]. In 2000, Udovic, Valant, and Suvorov conducted the research for the improvement of dielectric characteristics in the microwave region through the addition of the sintering additive, $\mathrm{TeO}_{2}$, into the $\mathrm{TiO}_{2}-\mathrm{TeO}_{2}$ system [8].

Regarding $\mathrm{TiTe}_{3} \mathrm{O}_{8}$ ceramics, the temperature coefficient of resonance frequency is $+50 \mathrm{ppm} /{ }^{\circ} \mathrm{C}$, which results in the susceptibility to temperature variation, despite the low sintering temperature $\left(760{ }^{\circ} \mathrm{C}\right)$, high electric constant $\left(\varepsilon_{\mathrm{r}}=42\right)$, and high quality factor $(35,000 \mathrm{GHz})$. Therefore, it is known to be an unsuitable microwave dielectric material. In this paper, eutectic phase with mixing of $\mathrm{MgTiO}_{3}$ ceramics $\left(\mathrm{Qf}=22,000 \mathrm{GHz}, \varepsilon_{\mathrm{r}}=16, \mathrm{TCRF}=-55 \mathrm{ppm} /{ }^{\circ} \mathrm{C}\right)$ was utilized to control the temperature coefficient of resonance frequency using a logarithmic mixing rule [9].

During the LTCC process, prolonged period of high sintering temperature can increase the electrical resistivity from the oxidation of $\mathrm{Ag}$ electrode; however, the time required for high sintering temperature should be minimized as much as possible [10]. $\mathrm{SnO}$ and $\mathrm{H}_{3} \mathrm{BO}_{3}$ is one of the well known low-temperature sintering additives, and a single component of this additive can decrease the dielectric 
performance due to the formation of new phase from preferred reaction with dielectric material. Therefore, the addition of complex components with more than two types has been reported to display superior performance and reduced sintering temperature at the same time [11].

In this study, the application of the logarithmic mixing rule on the $\mathrm{MgTiO}_{3}-\mathrm{TiTe}_{3} \mathrm{O}_{8}$ system using $\mathrm{SnO}$ and $\mathrm{H}_{3} \mathrm{BO}_{3}$, its microwave dielectric properties, and sintering temperature variation were investigated. Using $\mathrm{MgTiO}_{3}-\mathrm{TiTe}_{3} \mathrm{O}_{8}+$ $\mathrm{SnO}+\mathrm{H}_{3} \mathrm{BO}_{3}$ ceramics with low temperature sintering capability and exceptional dielectric property, the triplexer filter was designed and manufactured to evaluate the frequency response in the CDMA800, GPS, and PCS regions.

\section{Experimental}

The starting materials were high-purity (more than 99\%) $\mathrm{MgO}, \mathrm{TeO}_{2}, \mathrm{TiO}_{2}, \mathrm{SnO}$, and $\mathrm{H}_{3} \mathrm{BO}_{3}$. $\mathrm{MgO}, \mathrm{TeO}_{2}$, and $\mathrm{TiO}_{2}$ were stoichiometrically weighed and mixed for 24 hours in a ball mill with $\mathrm{ZrO}_{2}$ media to form the $\mathrm{TiTe}_{3} \mathrm{O}_{8}$ and $\mathrm{MgTiO}_{3}$, respectively. Mixed $\mathrm{TiTe}_{3} \mathrm{O}_{8}$ and $\mathrm{MgTiO}_{3}$ powders were dried and calcined at $650{ }^{\circ} \mathrm{C}$ and $1100{ }^{\circ} \mathrm{C}$ for 3 hours, respectively. The calcined $\mathrm{TiTe}_{3} \mathrm{O}_{8}$ and $\mathrm{MgTiO}_{3}$ powders and $\mathrm{SnO}, \mathrm{H}_{3} \mathrm{BO}_{3}$ were mixed with the compositional ratio, after which they were uniaxially pressed into a $12 \mathrm{~mm}$-diameter disk under the pressure of $800 \mathrm{~kg} / \mathrm{cm}^{2}$. The disks were sintered in air at $820{ }^{\circ} \mathrm{C}$ for 0.3 hours. These sintered samples were then polished. The bulk densities of the pellets were measured using the Archimedes method with deionized water. The crystalline structure were analyzed by X-ray diffraction (XRD) using a $\mathrm{CuK \alpha}$ emission. The microstructures of polished and thermally etched surfaces were observed by scanning electron microscope (SEM). Dielectric properties at the microwave frequency were measured using the Hakki and Colemann methods [12, 13]. A HPE5071B network analyzer was used for the microwave characteristic measurements. The dielectric constant can be determined accurately by measuring the resonant frequency of the $\mathrm{TE}_{011}$ mode and by verifying the $\mathrm{TE}_{01 \delta}$ resonant modes. The temperature coefficient of the resonant frequency was defined as follows:

$$
T C R F=\left(\frac{1}{f_{25}}\right) \cdot\left(\frac{\Delta f}{\Delta T}\right) \cdot 10^{6}\left(\mathrm{ppm} /{ }^{\circ} \mathrm{C}\right) .
$$

To investigate the possibility of the filter application, the triplexer was designed, simulated, and manufactured using Advanced Design System (ADS) and HFSS, which are used in the electro-magnetic analysis tool. The frequency response characteristics of the manufactured triplexer were then measured by vector network analyzer.

\section{Result and Discussion}

Fig. 1 shows the XRD results on $0.6 \mathrm{TiTe}_{3} \mathrm{O}_{8}-0.4 \mathrm{MgTiO}_{3}$ $+3 \mathrm{wt} \% \mathrm{SnO}$ with the addition of $\mathrm{H}_{3} \mathrm{BO}_{3}$. Firing temperature

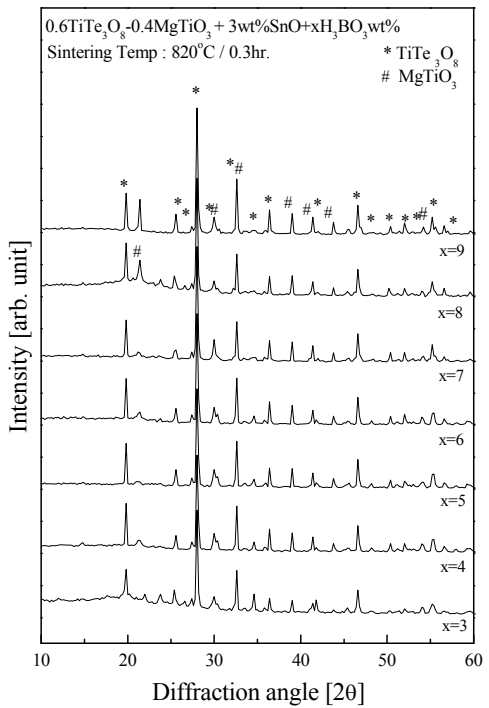

Fig. 1. $\mathrm{XRD}$ patterns of the $0.6 \mathrm{TiTe}_{3} \mathrm{O}_{8}-0.4 \mathrm{MgTiO}_{3}$ $+3 \mathrm{wt} \% \mathrm{SnO}+\mathrm{xwt} \% \mathrm{H}_{3} \mathrm{BO}_{3}$ ceramics.

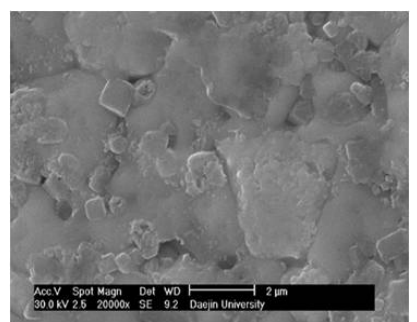

(a) $3 \mathrm{wt} \%$

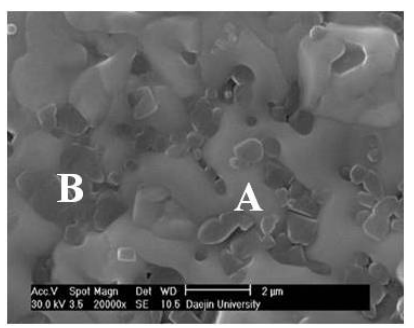

(c) $7 \mathrm{wt} \%$

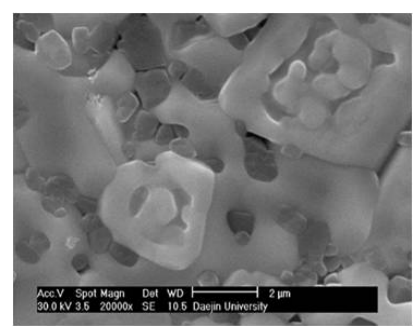

(b) $5 \mathrm{wt} \%$

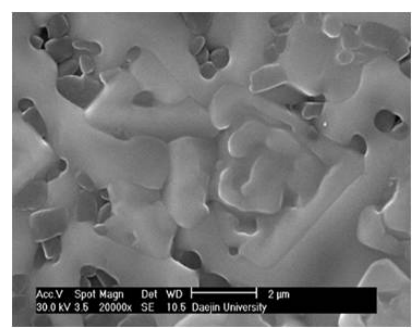

(d) $9 \mathrm{wt} \%$
Fig. 2. $\mathrm{SEM}$ images of the $0.6 \mathrm{TiTe}_{3} \mathrm{O}_{8}-0.4 \mathrm{MgTiO}_{3}$ $+3 \mathrm{wt} \% \mathrm{SnO}+\mathrm{xwt} \% \mathrm{H}_{3} \mathrm{BO}_{3}$ ceramics.

and holding time was $820^{\circ} \mathrm{C}$ and 0.3 hours, respectively. Overall, the $\mathrm{TiTe}_{3} \mathrm{O}_{8}$ and $\mathrm{MgTiO}_{3}$ phase without the secondary phase was found. The increase in weight percent of $\mathrm{H}_{3} \mathrm{BO}_{3}(\mathrm{wt} \%)$ resulted in the reduction in full width at half maximum (FWHM) and diffraction intensity of $\mathrm{TiTe}_{3} \mathrm{O}_{8}$ and $\mathrm{MgTiO}_{3}$. This phenomenon is considered to improve the crystallization of $0.6 \mathrm{TiTe}_{3} \mathrm{O}_{8}-0.4 \mathrm{MgTiO}_{3}+3 \mathrm{wt} \% \mathrm{SnO}$ ceramics, especially with the addition of the $\mathrm{H}_{3} \mathrm{BO}_{3}$ sintering additive. The most frequently adopted method for effective sintering is by using an additive material, the addition of which can form a solid solution in the matrix or liquid phase during sintering process to promote the process [14]. In this experiment, the addition of $\mathrm{H}_{3} \mathrm{BO}_{3}$ is considered to be related to the formation of the liquid phase 
due to the low melting point of $\mathrm{H}_{3} \mathrm{BO}_{3}$ (m.p. : $460^{\circ} \mathrm{C}$ ) rather than solid solution formation. The liquid phase is known to improve the crystalline growth of $\mathrm{TiTe}_{3} \mathrm{O}_{8}$ and $\mathrm{MgTiO}_{3}$ ceramics. In general, sintering additives with more than two components is acknowledged to improve microwave dielectric property and sintering characteristics compared with a single component. In this study, the addition of $\mathrm{SnO}$ and $\mathrm{H}_{3} \mathrm{BO}_{3}$ achieved a slightly lower sintering temperature $\left(830{ }^{\circ} \mathrm{C} \rightarrow 820{ }^{\circ} \mathrm{C}\right)$, and holding time was also reduced to 0.3 hours.

The microstructure of the $0.6 \mathrm{TiTe}_{3} \mathrm{O}_{8}-0.4 \mathrm{MgTiO}_{3}+$ $3 \mathrm{wt} \% \mathrm{SnO}+\mathrm{xwt}^{2} \% \mathrm{H}_{3} \mathrm{BO}_{3}$ ceramics is shown in Fig. 2. For every specimen, sufficiently dense morphology was obtained. This can be elucidated through the lower firing temperature $\left(820^{\circ} \mathrm{C}\right)$ and shorter holding time ( 0.3 hours), which were achieved because of the addition of $\mathrm{SnO}$ and $\mathrm{H}_{3} \mathrm{BO}_{3}$ compared with the sintering conditions of pure $0.6 \mathrm{TiTe}_{3} \mathrm{O}_{8}-0.4 \mathrm{MgTiO}_{3}\left(830{ }^{\circ} \mathrm{C}\right.$ and 3 hours $)$. The densification of the microstructure can be achieved in lower temperature. Reduced pore volume and densification via the addition of $\mathrm{H}_{3} \mathrm{BO}_{3}$ also affected the density and microwave dielectric constant.

To determine the composition of the crystalline grain, Energy Dispersive Spectroscopy (EDS) analysis was conducted on $0.6 \mathrm{TiTe}_{3} \mathrm{O}_{8}-0.4 \mathrm{MgTiO}_{3}+3 \mathrm{wt} \% \mathrm{SnO}+7 \mathrm{wt} \%$ $\mathrm{H}_{3} \mathrm{BO}_{3}$, which was sintered at $820{ }^{\circ} \mathrm{C}$ for 0.3 hours. The corresponding results are shown in Fig. 3. The bright region (grain A) shows the typical composition of $\mathrm{TiTe}_{3} \mathrm{O}_{3}$, and the dark region (grain $\mathrm{B}$ ) corresponded to the slight $\mathrm{Te}$ phase. However, it is considered to be the crystalline grain of the surrounding $\mathrm{TiTe}_{3} \mathrm{O}_{8}$ rather than the solid solution between $\mathrm{MgTiO}_{3}$ and Te. However, EDS, $\mathrm{TiTe}_{3} \mathrm{O}_{8}$ and $\mathrm{MgTiO}_{3}$ co-existed and did not form a solid solution. In addition, the added $\mathrm{H}_{3} \mathrm{BO}_{3}$ and $\mathrm{SnO}$ were not present in the specimen after conducting the sintering process. This can be elucidated by the X-ray diffraction pattern in Fig. 1, which does not show the pattern related to $\mathrm{SnO}$ and $\mathrm{H}_{3} \mathrm{BO}_{3}$.

Fig. 4 shows the sintering density and dielectric constant of $0.6 \mathrm{TiTe}_{3} \mathrm{O}_{8}-0.4 \mathrm{MgTiO}_{3}+3 \mathrm{wt} \% \mathrm{SnO}+\mathrm{xwt} \% \mathrm{H}_{3} \mathrm{BO}_{3}$. The addition of $\mathrm{H}_{3} \mathrm{BO}_{3}$ in $3-5 \mathrm{wt} \%$ displayed higher density than pure $0.6 \mathrm{TiTe}_{3} \mathrm{O}_{8}-0.4 \mathrm{MgTiO}_{3}$. The added $\mathrm{SnO}$ and $\mathrm{H}_{3} \mathrm{BO}_{3}$ formed the liquid phase during sintering, thus facilitating the sintering process. Overall, the higher content of $\mathrm{H}_{3} \mathrm{BO}_{3}$ resulted in reduced sintering density. This phenomenon could be explained through the lower molecular weight of $\mathrm{H}_{3} \mathrm{BO}_{3}$ (61.84) and lower melting point (m.p. $=185^{\circ} \mathrm{C}$ ), which was vaporized after promoting liquidphase sintering. The vaporization of the sintering additive also reduced sintering density. Regarding the dielectric constant, the addition of $\mathrm{H}_{3} \mathrm{BO}_{3}$ showed higher value compared with that of pure $0.6 \mathrm{TiTe}_{3} \mathrm{O}_{8}-0.4 \mathrm{MgTiO}_{3}$; however, the increase in $\mathrm{H}_{3} \mathrm{BO}_{3}$ content resulted in the reduction in constant. This phenomenon is similar to sintering density. The dielectric constant is determined by the composition of material and is affected by the size of the grain, pore $\left(\varepsilon_{\mathrm{r}}=1\right)$, and secondary phase [16].

The quality factor and temperature coefficient for the resonance frequency of $0.6 \mathrm{TiTe}_{3} \mathrm{O}_{8}-0.4 \mathrm{MgTiO}_{3}+3 \mathrm{wt} \% \mathrm{SnO}$

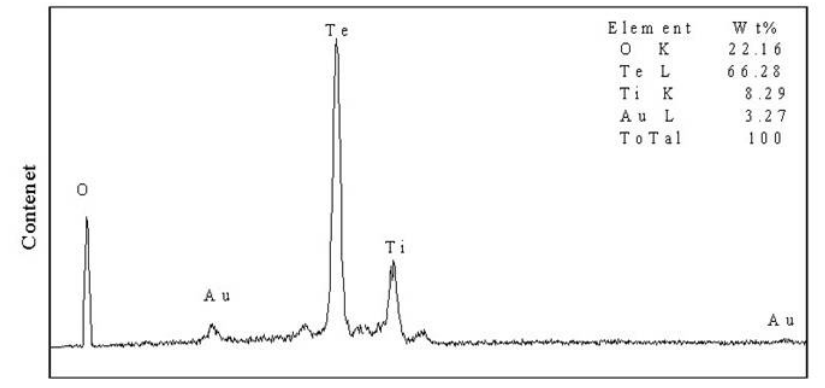

(a) A region

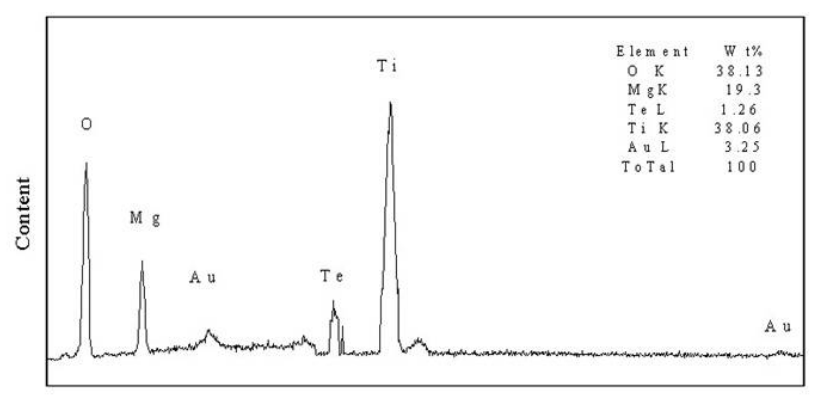

(b) B region

Fig. 3. EDS spectra of the $0.6 \mathrm{TiTe}_{3} \mathrm{O}_{8}-0.4 \mathrm{MgTiO}_{3}+$ $3 \mathrm{wt} \% \mathrm{SnO}+\mathrm{xwt} \% \mathrm{H}_{3} \mathrm{BO}_{3}$ ceramics.

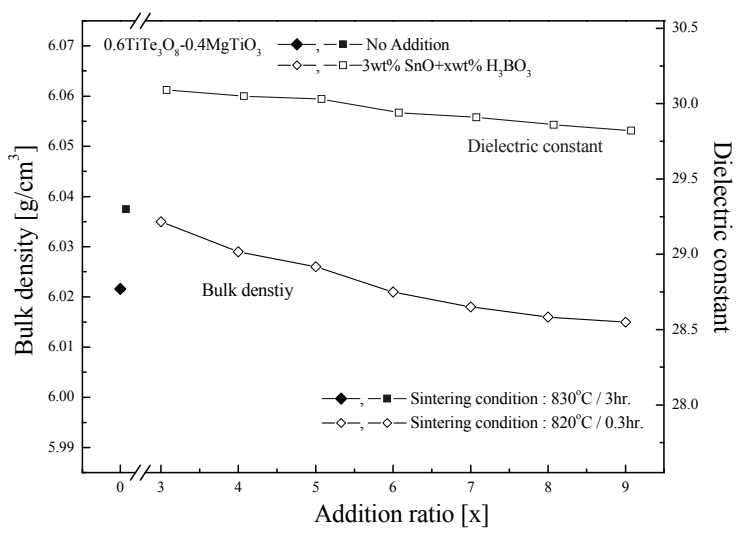

Fig. 4. Bulk density and dielectric constant of the $0.6 \mathrm{TiTe}_{3} \mathrm{O}_{8}-0.4 \mathrm{MgTiO}_{3}+3 \mathrm{wt} \% \mathrm{SnO}+\mathrm{xwt} \% \mathrm{H}_{3} \mathrm{BO}_{3}$ ceramics.

$+\mathrm{xwt} \% \mathrm{H}_{3} \mathrm{BO}_{3}$ ceramics are shown in Fig. 5. The addition of sintering additives, $\mathrm{H}_{3} \mathrm{BO}_{3}$, and $\mathrm{SnO}$ also reduced quality factor. In general, quality factor increases with density. However, a previous report has stated that there is no correlated result for this [17]. Dielectric loss of material is basically determined by attenuation constant, which is related to non-harmonic vibration of lattice. However, the polycrystalline dielectric material cannot be depicted by a single factor due to the presence of various effects, such as lattice defect, crystalline boundary, impurity, and so on. In this study, decrease in quality factor through the addition of $\mathrm{H}_{3} \mathrm{BO}_{3}$ and $\mathrm{SnO}$ occurred because of the increased loss at 
the crystalline boundary. This indicated that abnormal grain growth caused by improved sintering characteristics reduced the quality factor. Quality factor also improved when $\mathrm{H}_{3} \mathrm{BO}_{3}$ increased from $3 \mathrm{wt} \%$ to $5 \mathrm{wt} \%$. In addition, over $5 \mathrm{wt} \%$ of sintering additive induced the reduction of $\mathrm{Q}$ factor. The addition of $\mathrm{H}_{3} \mathrm{BO}_{3}$ in small quantity was related to relatively dense sintered body with increased grain size and less porosity that led to a corresponding high quality factor. More than $3 \mathrm{wt} \%$ of $\mathrm{H}_{3} \mathrm{BO}_{3}$ caused the reduction in quality factor due to the loss at grain boundary brought about by the abnormal grain growth.

For the temperature coefficient on resonance frequency, all compositions showed negative values. However, pure $0.6 \mathrm{TiTe}_{3} \mathrm{O}_{8}-0.4 \mathrm{MgTiO}_{3}$ without the sintering additive displayed a positive value, and the negative temperature coefficient corresponded to the addition of $\mathrm{H}_{3} \mathrm{BO}_{3}$ and $\mathrm{SnO}$. Along with the increase in added amount of $\mathrm{H}_{3} \mathrm{BO}_{3}$, temperature coefficient changed to a positive value. The low melting point of $\mathrm{H}_{3} \mathrm{BO}_{3}$ could be attributed to the vaporization of additive after completing the sintering process. Therefore, the impact on temperature coefficient was unnoticed. From these results, the negative value of the temperature coefficient for $0.6 \mathrm{TiTe}_{3} \mathrm{O}_{8}-0.4 \mathrm{MgTiO}_{3}$ $+3 \mathrm{wt} \% \mathrm{SnO}+\mathrm{xwt} \% \mathrm{H}_{3} \mathrm{BO}_{3}$ was related to the addition of $\mathrm{SnO}$. SnO showed a relatively high melting point (m.p.: $800{ }^{\circ} \mathrm{C}$ ) and remained inside the specimen even after the sintering process was finished. Thus, residual $\mathrm{SnO}$ might have an impact on temperature coefficient of resonance frequency.

According to the results, the dielectric constant, quality factor, and temperature coefficient of $0.6 \mathrm{TiTe}_{3} \mathrm{O}_{8^{-}}$ $0.4 \mathrm{MgTiO}_{3}+3 \mathrm{wt} \% \mathrm{SnO}+7 \mathrm{wt} \% \mathrm{H}_{3} \mathrm{BO}_{3}$, which was sintered at $820{ }^{\circ} \mathrm{C}$ for 0.3 hours exhibited values of $29.91,33,000$ $\mathrm{GHz}$ and $-2.76 \mathrm{ppm} /{ }^{\circ} \mathrm{C}$, respectively. This composition was utilized for the preparation of ceramic dielectric sheet for multi-layer chip filter.

Green sheet was produced using $0.6 \mathrm{TiTe}_{3} \mathrm{O}_{8}-0.4 \mathrm{MgTiO}_{3}$ $+3 \mathrm{wt} \% \mathrm{SnO}+7 \mathrm{wt} \% \mathrm{H}_{3} \mathrm{BO}_{3}$ ceramics with tape casting (Fig. 6). The slurry for tape casting was mixed with $0.6 \mathrm{TiTe}_{3} \mathrm{O}_{8}-$ $0.4 \mathrm{MgTiO}_{3}+3 \mathrm{wt} \% \mathrm{SnO}+7 \mathrm{wt} \% \mathrm{H}_{3} \mathrm{BO}_{3}$ powder and $\mathrm{PVB}$ binder system after 24 hours of ball-milling. The most common empirically determined solid loading (ratio of

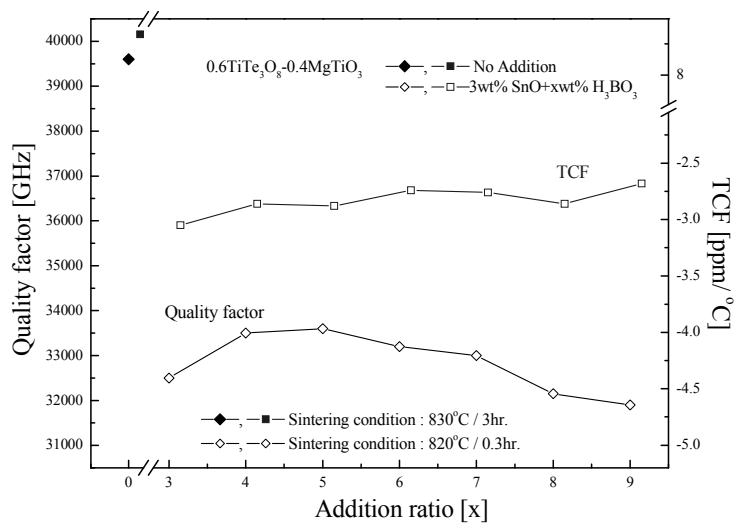

Fig. 5. Quality factor and TCF of the $0.6 \mathrm{TiTe}_{3} \mathrm{O}_{8-}$ $0.4 \mathrm{MgTiO}_{3}+3 \mathrm{wt} \% \mathrm{SnO}+\mathrm{xwt} \% \mathrm{H}_{3} \mathrm{BO}_{3}$ ceramics powder in slurry) for a multi-layer capacitor is $65 / 35$ of weight ratio. Thus, for this study, a $65 / 35$ mixing ratio was also adopted to prepare the slurry. The viscosity of the slurry is not only critical information to check the state of the slurry, but is also an important factor for the density of green sheet after casting. In our work, the viscosity of the slurry was controlled at $2,620 \mathrm{cps}$ to achieve the maximum

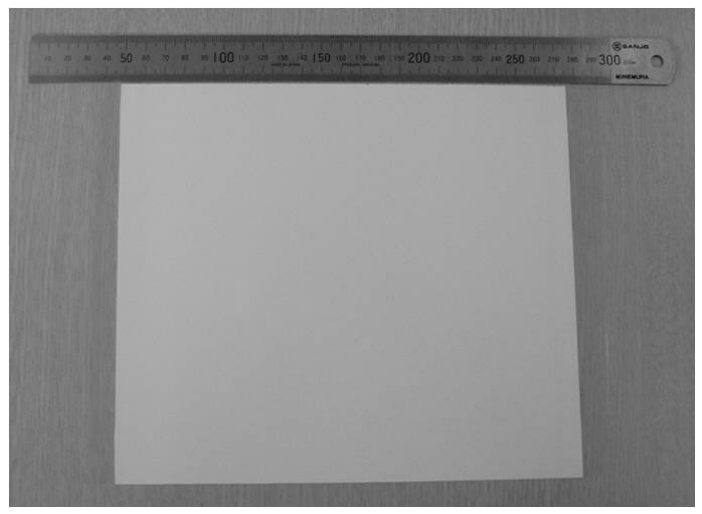

Fig. 6. Photograph of the manufactured green sheet with the $0.6 \mathrm{TiTe}_{3} \mathrm{O}_{8^{-}}-0.4 \mathrm{MgTiO}_{3}+3 \mathrm{wt} \% \mathrm{SnO}+7 \mathrm{wt} \% \mathrm{H}_{3} \mathrm{BO}_{3}$ ceramics.

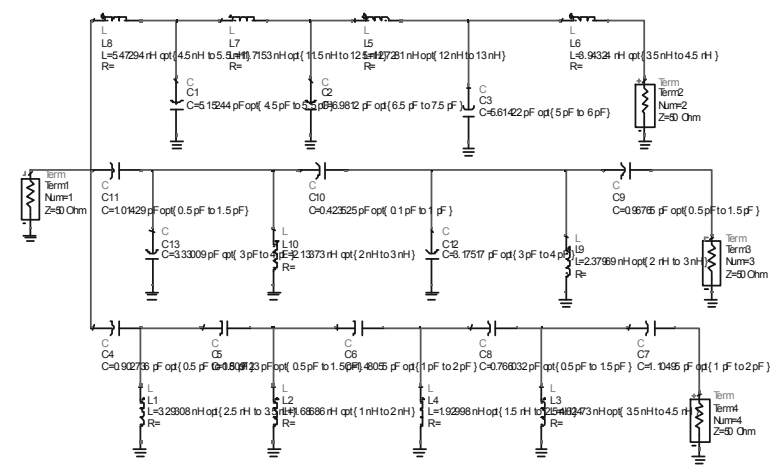

(a) Equivalent circuit

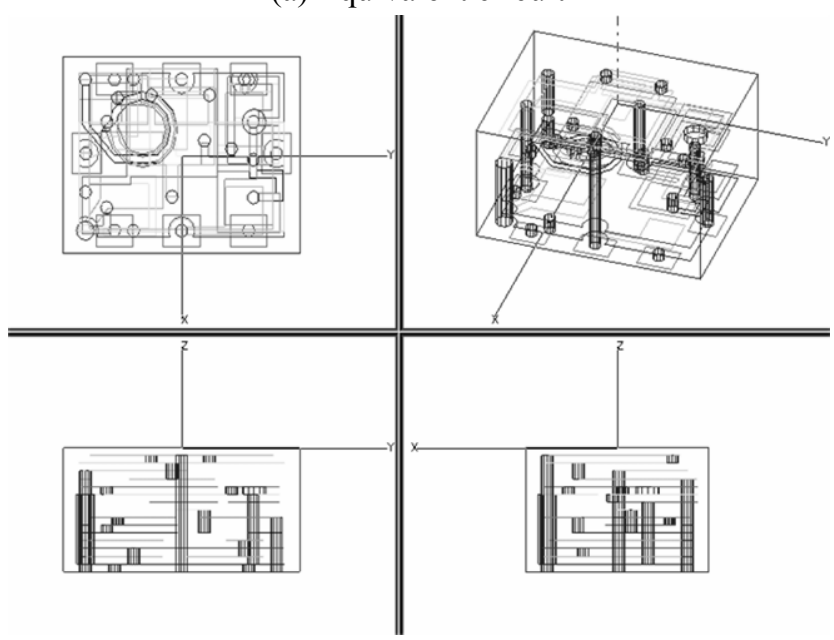

(b) Schematic

Fig. 7. Equivalent circuit (a) and schematic (b) of the triplexer. 


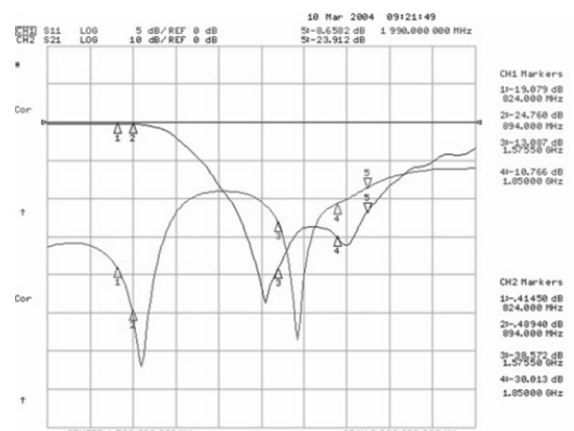

(a) CDMA800 band

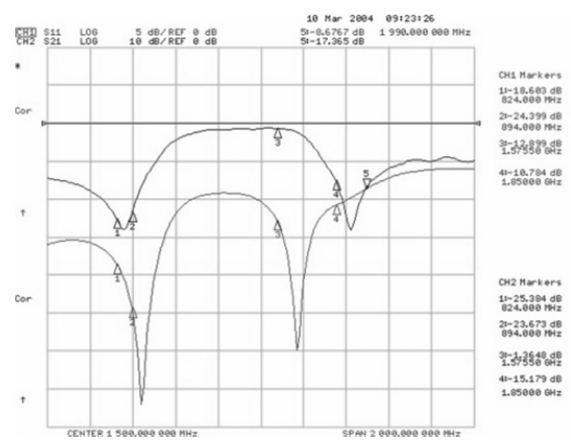

(b) GPS band

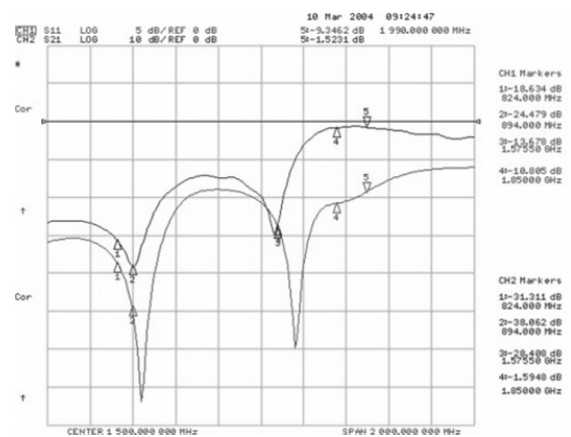

(c) PCS band

Fig. 8. Frequency characteristics of the manufactured triplexer filter.

density in green sheet. Powder and binder were mixed for 24 hours, and the green sheet was fabricated into a $100 \mu \mathrm{m}$ thick sheet on top of carrier film using tape caster (P.V.S Model 110).

Fig. 7 shows the equivalent circuit and design drawing for the simulation and fabrication of triplexer. From the design factor for the triplexer filter, circuit simulation was conducted using ADS (Fig. 7-a). The applicable frequency range of the triplexer filter; CDMA800, GPS and PCS ranges; LPF (low pass filter), BPF (band pass filter), and HPF (high pass filter) were all used for the design. The corresponding design drawing for the triplexer made of $0.6 \mathrm{TiTe}_{3} \mathrm{O}_{8}-0.4 \mathrm{MgTiO}_{3}+3 \mathrm{wt} \% \mathrm{SnO}+7 \mathrm{wt} \% \mathrm{H}_{3} \mathrm{BO}_{3}$ green sheet was drawn with HFSS (Fig. 7-b). Silver was chosen for the internal electrode. Including the top and bottom electrodes, 16 layers were designed for the CDMA800, GPS, and PCS ranges. The actual dimension of the triplexer was $3.23 \mathrm{~mm}$ in width, $2.52 \mathrm{~mm}$ in length, and 1.59
Table 1. Comparison of attenuation properties in the commercial and proposed triplexers

\begin{tabular}{c|c|c}
\hline $\begin{array}{c}\text { Attenuation } \\
\text { properties }\end{array}$ & $\begin{array}{c}\text { Commercial } \\
\text { triplexer }\end{array}$ & $\begin{array}{c}\text { Proposed } \\
\text { triplexer }\end{array}$ \\
\hline CDMA800 region & $30 \mathrm{~dB} @ \mathrm{GPS}$ & $38.57 \mathrm{~dB} @ \mathrm{GPS}$ \\
& $30 \mathrm{~dB} @$ PCS & $30.01 \mathrm{~dB} @$ PCS \\
\hline \multirow{2}{*}{ PCS region } & 30dB@CDMA800 & 25.38dB@CDMA800 \\
& $30 \mathrm{~dB} @$ PCS & $15.17 \mathrm{~dB} @$ PCS \\
\hline \multirow{2}{*}{ GPS region } & 30dB@CDMA800 & $31.31 \mathrm{~dB} @$ CDMA800 \\
& 30dB@GPS & $28.40 \mathrm{~dB} @$ GPS \\
\hline
\end{tabular}

$\mathrm{mm}$ in thickness.

Agilent $8753 \mathrm{E}$ network analyzer was used to determine the frequency characteristics of the triplexer filter (Fig. 8). Center frequency for measurement was $1,500 \mathrm{MHz}$, and the frequency range was within 2,000 MHz. The most important factor for triplexer filter measurement is attenuation characteristics rather than voltage standing wave ratio (VSWR). The triplexer with the unique frequency ranges should not act as filter for the specified frequency range, and other frequency ranges than the target one should not be blocked to generate noise. Therefore, filtering characteristics other than the specified frequency range should be restricted. The resulting values are $0.5 \mathrm{~dB}$ of insertion loss, 1.31 of VSWR, $38.572 \mathrm{~dB}$ (GPS) and $30.013 \mathrm{~dB}$ (PCS) of attenuation property for the CDMA 800 range; $1.36 \mathrm{~dB}$ of insertion loss, 1.8of VSWR, $25.384 \mathrm{~dB}$ (CDMA800) and $15.179 \mathrm{~dB}$ (PCS) for the GPS range; and $1.4 \mathrm{~dB}$ of insertion loss, 1.4 of VSWR, $31.311 \mathrm{~dB}$ (CDMA800) and 28.4 $\mathrm{dB}$ (GPS) for the PCS range.

To verify that the proposed compositions provide the improved dielectric properties for microwave application, a comparison of attenuation properties in commercial (MTX300LP of MTC, Inc.) and proposed triplexer is shown in Table 1. In the almost frequency region, the proposed triplexer shows superior attenuation properties compared with the commercial triplexer. With these results, it can be said that Ti-Te system ceramics can help achieve improved dielectric properties for microwave application.

\section{Conclusion}

In this study, $\mathrm{SnO}$ and $\mathrm{H}_{3} \mathrm{BO}_{3}$ were added to $0.6 \mathrm{TiTe}_{3} \mathrm{O}_{8}$ $0.4 \mathrm{MgTiO}_{3}$ for microwave ceramic dielectric, which was optimized for low-temperature sintering under $900{ }^{\circ} \mathrm{C}$. Using the tape casting method, the dielectric green sheet was manufactured with the addition of $\mathrm{SnO}$ and $\mathrm{H}_{3} \mathrm{BO}_{3}$. In addition, a triplexer for $800 \mathrm{MHz}$ and $2 \mathrm{GHz}$ was fabricated to evaluate frequency characteristics. When $\mathrm{H}_{3} \mathrm{BO}_{3}$ and $\mathrm{SnO}$ were added, higher sintering density and dielectric constant was achieved compared with pure $0.6 \mathrm{TiTe}_{3} \mathrm{O}_{8^{-}}$ $0.4 \mathrm{MgTiO}_{3}$. For quality factor, it was lower than pure $0.6 \mathrm{TiTe}_{3} \mathrm{O}_{8}-0.4 \mathrm{MgTiO}_{3}$. Along with increased amount of $\mathrm{H}_{3} \mathrm{BO}_{3}$, sintering density and dielectric constant of $0.6 \mathrm{TiTe}_{3} \mathrm{O}_{8}-0.4 \mathrm{MgTiO}_{3}+3 \mathrm{wt} \% \mathrm{SnO}+\mathrm{xwt} \% \mathrm{H}_{3} \mathrm{BO}_{3}$ ceramics were also reduced. The quality factor of $0.6 \mathrm{TiTe}_{3} \mathrm{O}_{8}-$ $0.4 \mathrm{MgTiO}_{3}+3 \mathrm{wt} \% \mathrm{SnO}+\mathrm{xwt}^{2} \mathrm{H}_{3} \mathrm{BO}_{3}$ increased in the 
range of $3<x<5$, but it was decreased with more than $5 \mathrm{wt} \%$. TCF achieved a negative value with the addition of $\mathrm{H}_{3} \mathrm{BO}_{3}$ and $\mathrm{SnO}$. Increase in added amount of $\mathrm{H}_{3} \mathrm{BO}_{3}$ was changed to a positive value. Sintering at $820{ }^{\circ} \mathrm{C}$ for 0.3 hours of $0.6 \mathrm{TiTe}_{3} \mathrm{O}_{8}-0.4 \mathrm{MgTiO}_{3}+3 \mathrm{wt} \% \mathrm{SnO}+7 \mathrm{wt} \% \mathrm{H}_{3} \mathrm{BO}_{3}$ showed good characteristics in dielectric constant (29.91), quality factor $(33,000 \mathrm{GHz})$, and TCF $\left(-2.76 \mathrm{ppm} /{ }^{\circ} \mathrm{C}\right)$.

Slurry with the powder to binder ratio of $65 / 35$ for $0.6 \mathrm{TiTe}_{3} \mathrm{O}_{8}-0.4 \mathrm{MgTiO}_{3}+3 \mathrm{wt} \% \mathrm{SnO}+7 \mathrm{wt} \% \mathrm{H}_{3} \mathrm{BO}_{3}$ was used in preparing green sheet using the tape casting method. The resulting triplexer from this green sheet exhibited superior frequency characteristics, such as $0.5 \mathrm{~dB}$ of insertion loss, 1.31 of VSWR, $38.572 \mathrm{~dB}$ (GPS) and $30.013 \mathrm{~dB}$ (PCS) of attenuation property for the CDMA800 range; $1.36 \mathrm{~dB}$ of insertion loss, 1.8of VSWR, $25.384 \mathrm{~dB}$ (CDMA800) and $15.179 \mathrm{~dB}$ (PCS) for the GPS range; and $1.4 \mathrm{~dB}$ of insertion loss, 1.4 of VSWR, $31.311 \mathrm{~dB}$ (CDMA800) and 28.4 $\mathrm{dB}$ (GPS) for the PCS range.

\section{Acknowledgements}

The present research has been conducted with the support of the Research Grant given by Kwangwoon University in 2010 .

\section{References}

[1] Sotoudeh Hamedi-High, Joseph Chung, Sooseok Oh, Ju-Ung Jo, Noh-Joon Park, Dae-Hee Park, "Design of a High Performance Patch Antenna for GPS Communication Systems", KIEE J. Electr. Eng. Technol., Vol. 4, No. 2, pp. 282-286, 2009.

[2] Y. Konish, "Novel Dielectric Waveguide Components-Microwave Applications of New Ceramic Materials", Proc. of IEEE, 79, pp. 726-740, 1991.

[3] R. E. Mistler, D. J. Shanefield and R. B. Runk, "Tape Casting of Ceramic", in Ceramic Processing Before firing : Edited by G. Y. Dnoda and L. L. Hench, Widly, New York, 1978.

[4] R. D. Richtmyer, "Dielectric Resonators", J. Appl. Phys., 10(1), pp. 391-395, 1939.

[5] H. Kagata, T. Inoue, et al., "Low-fire dielectric ceramics for multilayer microwave devices", Jpn. Nat. Tech. Report, 40, pp. 17-22, 1994.

[6] R. S. Roth, J. L. Waring, "Phase Equilibrium Relations In The Binary System Bismuth Sesquioxide Niobium Pentoxide”, J. Res. Nat. Bur. Stand., 66, pp. 451-463, 1962.

[7] S. Yamanaka, M. Miyake, "Study of the ternary TiTe-O system", J. Less-Common Metall., 159, pp. 179-189, 1990.

[8] M. Udovic, M. Valant, D. Suvorov, "Dielectric characterisation of ceramics from the $\mathrm{TiO}_{2}-\mathrm{TeO}_{2}$ system", J. Euro. Ceram. Soc., 21, pp. 1735-1738, 2001.

[9] Giovanni B. Andreozzi et al., "High-temperature electrical conductivity of $\mathrm{FeTiO}_{3}$ and ilmenite", Journal of Materials Chem. Vol.6(6), pp. 987-991, 1996.

[10] G. Zablotny, "Improving Yields in Cofired Ceramic Packages: An Examination of Process and Equipment”, Hybrid Circuit Tech., 9, pp. 33-35, 1992.

[11] Q. H. Yang, E. S. Kim, Y. J. Kim, "Effect of PbO$\mathrm{B}_{2} \mathrm{O}_{3}-\mathrm{V}_{2} \mathrm{O}_{5}$ Glass on the Microwave Dielectric Properties of $(\mathrm{Pb}, \mathrm{Ca}, \mathrm{La})(\mathrm{Fe}, \mathrm{Nb}) \mathrm{O}_{3}$ Ceramics", Mater. Sci. \& Eng. B, pp. 161-166, 2002.

[12] B. W. Hakki and P. D. Coleman, "A Dielectric Resonator Method of Measuring Inductive Capacities in the Millimeter Range", IRE Trans. on Microwave Theory and Technique, Vol.MTT-24, No.10, pp. 402410, 1960.

[13] Y. Kobayashi and M. Katoh, "Microwave Measurement of Dielectric Properties of Low-Loss Materials by the Dielectric Rod Resonator Method", IEEE Trans. on Microwave Theory and Techniques, Vol. MTT-33, No. 7, pp. 586-592, 1985.

[14] Cheng-Liang Huang and Ming-Hung Weng, "Improved high $\mathrm{Q}$ value of $\mathrm{MgTiO}_{3}-\mathrm{CaTiO}_{3}$ microwave dielectric ceramics at low sintering temperature", Mater. Res. Bull., 36, pp. 2741-2750, 2001.

[15] Heli Jantunen et al., "Compositions of $\mathrm{MgTiO}_{3}$ $\mathrm{CaTiO}_{3}$ ceramic with two borosilicate glasses for LTCC technology", J. Euro. Ceram. Soc., 20, pp. 2331-2336, 2000.

[16] J. M. Wu, "Reaction Sequence and Effect of Calcination and Sintering on Microwave Properties of (Ba,Sr)O-Sm ${ }_{2} \mathrm{O}_{3}-\mathrm{TiO}_{2}$ Ceramics", J. Am. Ceram. Soc., 73, pp1599-1605, 1990.

[17] Chien-Min Cheng, Shi-Hong Lo and Cheng-Fu Yang, "The effect of $\mathrm{CuO}$ on the sintering and properties of $\mathrm{BiNbO}_{4}$ microwave ceramics", Ceram. International, 26, pp. 113-117, 2000.

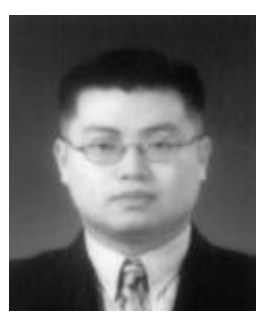

Eui-Sun Choi received his M.S. and Ph.D. degrees in Electronic Materials Engineering from Kwangwoon University. His research interests include microwave dielectric ceramics, LTCC, antennas, and RFID.

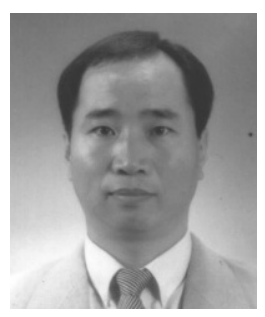

Moon-Woo Lee received his M.S. degree in Electronic Engineering from Soongsil University and his Ph.D. degree in Information and Communication Engineering from Paichai University. He is a professor at the Department of Ubiquitous Communication at Seoul Jeongsu College of Korea Polytechnic I . His research interests include sensors, antennas, and RFID. 


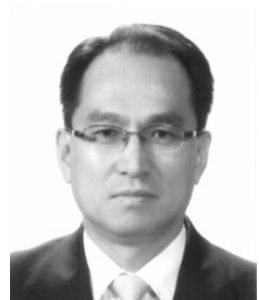

Sang-Hyun Lee received his B.S. and M.S. degrees in Electronic Communication Engineering from Hanyang University. He is a professor at the Department of Ubiquitous Communication at Seoul Jeongsu College of Korea Polytechnic I . His research interests include sensors, antennas, and RFID.

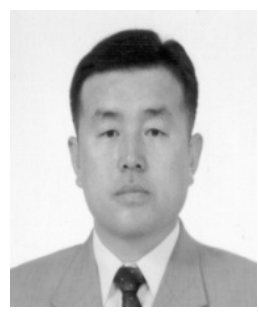

Gu-Hong Kang received his M.S. and $\mathrm{Ph} . \mathrm{D}$. degrees in Electronic Engineering from Kwangwoon University and Kangwon National University, respectively. He is a professor at the Department of Photoelectron at Seongnam College of Korea Polytechnic I . His research interests include sensors, antennas, and RFID.

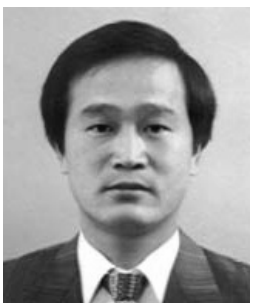

Gap-Sul Kang received his M.S degree in Mechanical Engineering from Sunchon National University. $\mathrm{He}$ is a professor at the Department of Computer-Aided Machining at Hwaseong College of Korea Polytechnic II . His research interests include sensors, antennas, and RFID.

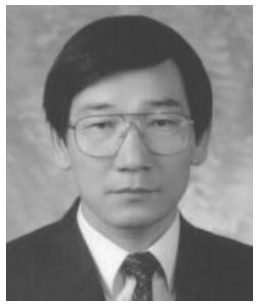

Young-Hie Lee received his M.S. and $\mathrm{Ph} . D$. degrees in Electrical Engineering from Yonsei University. He is a professor at the Department of Electronic Materials Engineering at Kwangwoon University in Seoul, Korea. His research interests include sol-gel processing, piezoelectric ceramics, thin film, microwave dielectric ceramics, sensors, and memory. 